\title{
Assimilation in the Djelfa Dialect of Algerian Arabic: An OT Account
}

\author{
Slimani Khedidja ${ }^{*}$, Jisheng Zhang \\ School of Foreign Languages, East China Normal University, China
}

Copyright $(2017$ by authors, all rights reserved. Authors agree that this article remains permanently open access under the terms of the Creative Commons Attribution License 4.0 International License

\begin{abstract}
The Djelfa dialect (DJ) is one of the varieties of Algerian Arabic that is characterized by complicated regressive and progressive assimilatory processes. The current paper addresses some of these assimilatory mechanisms; namely, nasal assimilation, lateral assimilation, /t/ assimilation, devoicing assimilation, emphasis assimilation and guttural place assimilation. The paper offers a straightforward analysis and provides a comprehensive picture of these assimilatory processes within the framework of Optimality Theory (OT), [1] [2], [3] and [4] by means of accounting for the trigger motivating them, which is reflected through the relevant constraints at play and their way of interaction. The paper concludes that regressive assimilation is very pervasive in the dialect as the latter endeavors to abide by IDENT-STEM-ONS (F) and IDENT-ONS (F) as much as possible unless a higher ranked constraint is endangered. Moreover, the paper lends support to McCarthy and Prince's (1995) claim that root faithfulness outranks affix faithfulness as DJ prefers to keep stem segment features intact at the expense of affix features change.
\end{abstract}

Keywords Djelfa Dialect, Regressive and Progressive Assimilation, Constraints, Optimality Theory

\section{Introduction}

Assimilation is known to be the influence of the articulation of a segment upon another in the way that one segment becomes identical to another in one or more phonetic features. The core issues pursued in this paper revolve around some regressive and progressive assimilatory processes attested in DJ. It is to the credit of OT that assimilation is adequately motivated. The cornerstone assumption of OT is that there are only two levels of representation input and output that are evaluated via a set of constraints to yield the optimal outputs. Since constraints are universal, DJ may differ from other languages only in terms of the hierarchal ranking of its constraints.

As far as I know, no one has dealt with assimilation in the dialect under scrutiny and this is the crucial rationale motivating such an investigation. The data used in this paper are collected by the author himself, being a native speaker of the dialect, and which may contribute in one way or another to the comparative studies of Arabic dialectology. The current paper revolves around two main questions (i) what are the assimilatory processes attested in the dialect (ii) how they are accounted for within OT. To put it differently, how the conflicting constraints interact with each other to yield the desired outputs.

The paper falls into two parts. The first part provides a detailed account of some regressive assimilatory processes attested in the dialect, viz., nasal assimilation, lateral assimilation, $/ \mathrm{t} /$ assimilation and devoicing assimilation and how the markedness and the faithfulness constraints interact with each other to yield the optimal outputs. The second part addresses some progressive assimilatory processes; namely, emphatic assimilation and guttural place assimilation and how OT adequately accounts for them.

\section{Regressive Assimilation in DJ}

\subsection{Nasal Assimilation}

In DJ, the alveolar nasal $/ \mathrm{n} /$ either fully or partially assimilates to some of the segments it immediately precedes. The motivation triggering these partial and total assimilations is accounted for in this section.

\subsubsection{Partial Assimilation}

DJ undergoes partial assimilation by means of which the alveolar nasal $/ \mathrm{n} /$ shares the place feature of the following obstruent segments: /b/, /k/,/g/ or /f/. In this respect, when /n/ is followed by the voiced bilabial plosive $/ \mathrm{b} /$, the velar plosives $/ \mathrm{k} /$ and $/ \mathrm{g} /$ or the labio-dental fricative /f/, the place feature of these segments spreads leftwards and hence, the original $/ \mathrm{n} /$ surfaces as $/ \mathrm{m} /, / \mathrm{h} /$ and $/ \mathrm{m} /$ respectively. It is 
important to note here that this place assimilation either takes place within one word or across a word boundary. Consider the data in (1a) and (1b).

\section{1) (a) Partial assimilation within one word}

\begin{tabular}{|c|c|c|}
\hline Input & Output & Gloss \\
\hline qanbu:la & qambu:la & 'bomb' \\
\hline junkur & jugkur & 'he denies' \\
\hline Yangu:d & Saygu:d & 'cluster' \\
\hline mangu:l & mangu:1 & 'taken from' \\
\hline janfaS & jamfaS & 'it benefits' \\
\hline
\end{tabular}

(b) Partial assimilation across a word boundary

\begin{tabular}{|c|c|c|}
\hline Input & Output & Gloss \\
\hline min bla:di & mim bla:di & 'from my country' \\
\hline wi:n ba:؟ & wi:m ba:؟ & 'where did he sell?' \\
\hline ka:n kbi:r & ka:y kbi:r & 'he was big' \\
\hline Jku:n kallam & Jku:n kallam & 'who called?' \\
\hline min gassam & min gassam & 'when he distributed' \\
\hline Jku:n ga:1 & Jku:n ga:l & 'who said?' \\
\hline min fa:t & mim fa:t & 'when he passed by' \\
\hline min ftah & mim ftah & 'when he opened' \\
\hline
\end{tabular}

This nasal place assimilation only targets the alveolar nasal $/ \mathrm{n} /$ as the place feature of the bilabial nasal $/ \mathrm{m} /$ is kept intact when followed by the velar plosives $/ \mathrm{g} /$ and $/ \mathrm{k} /$ and the labiodentals fricative /f/. Consider the data in (2).

2)

\begin{tabular}{|c|c|c|}
\hline Input & Output & Gloss \\
\hline kla:m ga:si & kla:m ga:si & 'tough words' \\
\hline Cla:m kbi:r & Gla:m kbi:r & 'a big flag' \\
\hline jkallam fi:h & jkallam fi:h & 'he is calling him' \\
\hline
\end{tabular}

As revealed in the data in (1a) and (1b), the alveolar nasal $/ \mathrm{n} /$ assimilates to the following obstruent segments in terms of the place feature. In order to capture this nasal assimilation by a constraint, we refer to the markedness constraint SHARE (F)

\section{3) SHARE(F) [5]}

Assign one violation mark for every pair of adjacent elements that are not linked to the same token of [f].

This constraint bans the adjacency of two segments that do not share the same features. To account for the $\mathrm{N}+\mathrm{O}$ distribution in the data above, we propose the following constraint:

\section{4) N-O SHARE(place)}

When a coronal nasal is followed by an obstruent, they should be linked to the same place feature.
This markedness constraint should be ranked very high in the dialect. In order to satisfy N-O SHARE (place), DJ may delete one of the adjacent segments, either $/ \mathrm{n} /$ or the obstruent segment following it, but this option is quite hopeless in the dialect as it is prone to violate the anti-deletion constraint MAX-IO.

\section{5) MAX-IO [4]}

Every segment of the input has a correspondent in the output.

(No phonological deletion)

As revealed in the data in (1a) and (1b), DJ secures N-O SHARE (place) through assimilation. It follows from this that MAX-IO should outrank IDENT-IO; otherwise N-O SHARE (place) will be satisfied via elision rather than assimilation.

\section{6) IDENT-IO}

Correspondent segments of input and output should be identical.

After recalling the relevant constraint, the following constraint hierarchy is borne out.

\section{7) N-O SHARE (place) $>>$ MAX-IO $>>$ IDENT-IO}

Table 1 tests the interaction of these markedness and faithfulness constraints to optimize the winner candidate from the input /qanbu:la/ 'bomb'.

Table 1. Constraint tableau: /qanbu:la/ $\rightarrow$ [qambu:la]/[qandu:la]

\begin{tabular}{|c|c|c|c|}
\hline /qanbu:la/ & $\begin{array}{c}\text { N-O SHARE } \\
\text { (place) }\end{array}$ & MAX-IO & IDENT-IO \\
\hline a. qanbu:la & $* !$ & & \\
\hline b. qabu:la & & $* !$ & \\
\hline (-) c. qandu:la & & & $*$ \\
\hline ;) d. qambu:la & & & $*$ \\
\hline
\end{tabular}

As it turns out from the constraint tableau above, the constraint hierarchy established in (7) is not sufficient to select the desired output since both of the candidates (c) and (d) are still competing for optimization in that they both satisfy the highly ranked constraint N-O SHARE (place) by segmental feature change: candidate (c) changes the place feature of the bilabial plosive to be homorganic with the preceding alveolar nasal while candidate (d) changes the place feature of the nasal segment to be homorganic with the following bilabial plosive. The fact that DJ optimizes [qambu:la] over [qandula] reflects the dialect's preference for keeping onset features unchanged. Consequently, another version of IDENT-IO should come to play.

\section{8) IDENT-ONS (F)}

Onset features should be kept intact.

Integrating IDENT-ONS (F) within the hierarchy already established in (7) yields the following dominance hierarchy which is further testified in table 2. 


\section{9) N-O SHARE (place) $>>$ MAX-IO $>>$ IDENT-ONS (F) $>>$ IDENT-IO}

Table 2. Constraint tableau: /qanbu:la/ $\rightarrow$ [qambu:la]

\begin{tabular}{|c|c|c|c|c|}
\hline /qanbu:la/ & $\begin{array}{c}\text { N-O } \\
\text { SHARE } \\
\text { (place) }\end{array}$ & MAX-IO & $\begin{array}{c}\text { IDENT-ONS } \\
\text { (F) }\end{array}$ & IDENT-IO \\
\hline a. qanbu:la & $* !$ & & & \\
\hline b. qabu:la & & $* !$ & & \\
\hline c. qandu:la & & & $*$ & \\
\hline $\begin{array}{c}\text { d. } \\
\text { qambu:la }\end{array}$ & & & & $*$ \\
\hline
\end{tabular}

Being faithful to the highly ranked constraints and incurring the least violation of IDENT-IO optimize candidate (d) over all its rivals.

\subsubsection{Total Assimilation}

In DJ, the alveolar nasal $/ \mathrm{n} /$ also undergoes total assimilation when it is followed by the following sonorant segments: the approximants $/ 1 /, / r /$ and the bilabial nasal $/ \mathrm{m} /$ which leads to gemination. But unlike the partial assimilation of the coronal nasal $/ \mathrm{n} /$ that takes place either within a word or across a word boundary, the total assimilation of $/ \mathrm{n} /$ only takes place across a word boundary. Consider the data in (10).

\section{0) Assimilation of $/ \mathbf{n} /$ across a word boundary}

\begin{tabular}{|c|c|c|}
\hline Input & Output & Gloss \\
\hline $\min$ lo:r & mil lo:r & 'from behind' \\
\hline ka:n la:bis & ka:1 la:bis & 'he was wearing' \\
\hline wi:n ra:h & wi:r ra:h & 'where did he go?' \\
\hline min rbih & mir rbih & 'when he won' \\
\hline Jku:n ma:t & fku:m ma:t & 'who died?' \\
\hline Jku:n mYa:k & Jku:m mৎa:k & 'who is with you?' \\
\hline
\end{tabular}

It is important to note here that the total nasal assimilation we are dealing with here only targets the alveolar nasal $/ \mathrm{n} /$ as the bilabial nasal $/ \mathrm{m} /$ does not undergo assimilation when it occurs in the vicinity of the sonorants / $/$ and $/ \mathrm{r} /$ across a word boundary. Consider the data in (11).
11)

\begin{tabular}{|c|c|c|}
\hline Input & Output & Gloss \\
\hline hlim ro:ho & ћlim ro:ho & 'he dreamt himself' \\
\hline $\begin{array}{c}\text { kla:m } \\
\text { raz3a:la }\end{array}$ & $\begin{array}{c}\text { kla:m } \\
\text { ra33a:la }\end{array}$ & 'men's words' \\
\hline sja:m la:zim & sja:m la:zim & 'fasting is a must' \\
\hline la:m Lubna & la:m Lubna & 'he blamed Lubna' \\
\hline
\end{tabular}

The data in (10) reveal that DJ does not allow the coronal nasal $/ \mathrm{n} /$ to be followed by the sonorant segments $/ \mathrm{l} /, \mathrm{r} / \mathrm{and}$ $/ \mathrm{m} /$ across a word boundary and accordingly, total assimilation is in order. To account for this total assimilation within OT, we are in need for a markedness constraint that bans the nasal $/ \mathrm{n} /$ from being followed by the sonorants $/ 1 /, / \mathrm{r} /$ and $/ \mathrm{m} /$. To this end, we propose the following constraint:

\section{2) $* \mathrm{~N}+\mathrm{SC}$}

Coronal nasal $/ \mathrm{n} /$ cannot be followed by a sonorant consonant across a word boundary except $/ \mathrm{n} /$.

The markedness constraint $* \mathrm{~N}+\mathrm{SC}$ militates against IDENT-IO that strives for the congruency between input and output. To satisfy the highly ranked constraint $* \mathrm{~N}+\mathrm{SC}$, DJ may simply elide the sonorant or the nasal segment, but elision is not the right move here as it incurs a fatal violation of MAX-IO. Another strategy the dialect may resort to resides in inserting a vowel to separate the nasal $/ \mathrm{n} /$ from the following sonorant consonant but, vowel epenthesis violates DEP-IO and, in turn, results in the wrong output.

\section{3) DEP-IO [4]}

Every segment of the output has a correspondent in the input.

(Prohibits phonological epenthesis)

To cope with this problem and secure *N+SC, DJ rather opts for total assimilation. Yet *N+SC can be satisfied either by regressive assimilation whereby inputs such as /min ra:h/ surfaces as [mir ra: $\hbar$ ] or by progressive assimilation by means of which the input /min ra: $\hbar /$ surfaces as [min na: $\hbar$ ]. But when $\mathrm{N}$ and $\mathrm{C}$ in VNCV have to be identical in features, DJ chooses to change the features of the coda nasal consonant and keeps those of the onset sonorant segment intact which is captured by IDENT-ONS(F) $>>$ IDENT-IO as in (9). Having recalled all the relevant constraints, the following constraint hierarchy is adduced.

\section{4) $* \mathbf{N}+$ SC $>>$ MAX-IO $>>$ DEP-IO $>>$ IDENT-ONS (F) $>>$ IDENT-IO}

Table 3. Constraint tableau: $/ \mathrm{min} \mathrm{ra}: \mathrm{h} / \rightarrow$ mir ra: $\hbar]$

\begin{tabular}{|c|c|c|c|c|c|}
\hline /min ra: $\hbar /$ & $* \mathrm{~N}+\mathrm{SC}$ & MAX-IO & DEP-IO & IDENT-ONS(F) & IDENT-IO \\
\hline a. min ra:h & $* !$ & & & & \\
\hline b. mi ra: $\hbar$ & & $* !$ & & & \\
\hline c. mini ra:h & & & $*$ & & \\
\hline d. min na:h & & & & $*$ & * \\
\hline e. mir ra:h & & & & & $*$ \\
\hline
\end{tabular}


Candidate (a) is definitely ruled out because it contravenes $* \mathrm{~N}+\mathrm{SC}$. Candidates (b) and (c) try to secure ${ }^{*} \mathrm{~N}+\mathrm{SC}$; the former by eliding the nasal segment and the latter by inserting /i/ to separate $/ \mathrm{n} /$ and $/ \mathrm{r} /$. Yet, neither of them is satisfactory as they breach MAX-IO and DEP-IO respectively. Candidate (d) also loses the competition as it breaches IDENT-ONS (F) by means of changing the onset $/ \mathrm{r} /$ into a nasal. Abiding by the highly ranked constraints, candidate (e) surfaces as the optimal output as it incurs the least violation.

\subsection{Lateral Assimilation}

DJ displays lateral assimilation whereby the lateral segment / $/$ of both of the definite article / $\mathrm{Pil} /$ and the enclitic /1/ get fully assimilated to some segments they are concatenated to. Let's first see how /1/ of the definite article undergoes assimilation in DJ and what kind of segments trigger and block such an assimilatory process.

The lateral $/ 1 /$ of the definite article undergoes total assimilation when it is immediately followed by some coronal segments. According to traditional Arab grammarians, consonants in Arabic are either 'solar' or 'lunar' sounds. Such classification rests upon whether these consonants do or do not trigger full assimilation [6]. Solar consonants are: $/ \mathrm{t}, \mathrm{d}, \mathrm{t}^{\mathrm{\varsigma}}, \mathrm{d}^{\mathrm{\varsigma}}, \mathrm{\partial}, \mathrm{s}, \mathrm{z}, \mathrm{s}^{\mathrm{s}}, \mathrm{\partial}^{\mathrm{s}}, \int, \mathrm{n}, \mathrm{l}, \mathrm{r} /$ while lunar consonants include:/b, k, q, g, f, $3^{2}, \mathrm{y}, \mathrm{x}, \hbar, \mathrm{\uparrow}, \mathrm{h}, \mathrm{m}, \mathrm{P} / \mathrm{In}$ the light of the adduced classification, the lateral $/ 1 /$ of the definite article $/ \mathrm{Pil} /$ in DJ fully assimilates to all solar consonants in addition to the voiced fricative $/ 3 /$. Assimilation, however, is blocked when $/ 1 /$ is prefixed to lunar sounds. Consider the data in (15.a) and (15.b).

15) (a) $\mathrm{ill}+$ coronal consonants

\begin{tabular}{|c|c|c|}
\hline Input & Output & Gloss \\
\hline Pil-ta:3 & Pitta:3 & 'the crown' \\
\hline Pil-dra:him & Piddra:him & 'the money' \\
\hline Pil-t'i:n & Pittiti:n & 'the mud' \\
\hline Pil-ði:b & Рiðði:b & 'the wolf' \\
\hline Pil-ð૬i:f & Рiðৎðఁi:f & 'the guest' \\
\hline Pil-sa:Ya & Pissa:Ya & 'the watch' 'the hour' \\
\hline Pil-s`a:hib & $\operatorname{Pis}^{\complement} s^{\complement} a: h i b$ & 'the friend' \\
\hline Pil-zi:n & Pizzi:n & 'the beauty' \\
\hline Pil-ni:f & Pinni:f & 'the nose' \\
\hline Pil-rmal & Pirrmal & 'the sand' \\
\hline Pil-lu:z & Pillu:z & 'the almonds' \\
\hline Pil-zbal & Pizzbal & 'the mountain' \\
\hline Pil- $\int a 9 b$ & 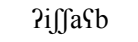 & 'the people' \\
\hline
\end{tabular}

1 DJ phonemic inventory lacks the emphatic segment $/ \mathrm{d}^{\mathrm{s}} /$ and tends to replace it with the emphatic fricative $/ \mathrm{\nearrow}^{\varsigma} /$.

$2 / 3 /$ is classified by Arab grammarians as a lunar sound as it does not assimilate to the definite article in Standard Arabic, however, in DJ, it triggers full assimilation. (b) Pil + non-coronal consonants

\begin{tabular}{|c|c|c|}
\hline Input & Output & Gloss \\
\hline Pil-ba:b & Pilba:b & 'the door' \\
\hline Pil-ma:kla & Pilma:kla & 'the food' \\
\hline Pil-kram & Pilkram & 'the hospitality' \\
\hline Pil-qafla & Pilqafla & 'the button' \\
\hline Pil-gbar & Pilgbar & 'the cemetery' \\
\hline Pil-fa:r & Pilfa:r & 'the mouse' \\
\hline Pil-xi:ma:r & Pilxi:ma:r & 'the scarf' \\
\hline Pil-hi:t' & Pilhi:t' & 'the wall' \\
\hline Pil-\{sal & Pil؟sal & 'the honey' \\
\hline
\end{tabular}

A quick look at the data above reveals that total assimilation takes place when /1/ is followed by coronal consonants and no assimilation takes place when $/ 1 /$ is followed by non-coronal consonants. Furthermore, this assimilatory process is restricted in terms of its application as it takes place only across morpheme boundaries and does not apply morpheme internally, as illustrated in the data in (16).

16)

\begin{tabular}{|c|c|c|c|}
\hline Input & Output & Output & Gloss \\
\hline 1sa:n & lsa:n & *ssa:n & 'tongue' \\
\hline 1зa:m & 1зa:m & *3za:m & 'bridle' \\
\hline
\end{tabular}

It follows from this that DJ does not allow the lateral $/ 1 /$ to be followed by a coronal segment across a morpheme boundary and rather requires them to share the same features. Let's take the glide /r/ as an example. Note that both /1/ and $/ \mathrm{r} /$ are approximants but they can be distinguished from each other in terms of the feature lateral; /1/ being [+lat] while /r/ being [-lat]. So, by means of assimilation, the [-lat] feature spreads leftward to the lateral /1/ which, in turn, becomes [r]. To cast this assimilatory process in the light of OT, we again make recourse to the markedness constraint SHARE $(F)$ and propose the constraint [LAT COR] SHARE (F) that can be stated as follows:

\section{7) [LAT COR] SHARE (F)}

Across a morpheme boundary, /1/ and the following coronal consonant should be assigned the same token features.

This constraint is in constant conflict with the faithfulness constraint IDENT-IO that calls for the identity between input and output. As reflected in the data above, [LAT COR] SHARE (F) is highly ranked in the hierarchy and hence, dominates IDENT-IO. 
To satisfy the highly ranked constraint [LAT COR] SHARE (F), DJ could have opted for inserting a vocalic segment to avoid the adjacency of a lateral and a coronal segment across a morpheme boundary. But inserting a segment results in the wrong output and, in turn, breaches DEP-IO. [LAT COR] SHARE (F) can be also satisfied by deleting one of the two adjacent segments; yet, this elision again results in an ill-formed structure and militates against MAX-IO that bans deletion of any sort. The least costly strategy the dialect resorts to is segmental feature change. Again IDENT-ONS (F) is what decides on the direction of assimilation as the dialect prefers to keep onset features intact. This assimilatory process is clearly captured by the constraint dominance hierarchy in (18) that is further testified in table 4 .

\section{8) [LAT COR] SHARE (F)>>MAX-IO>>DEP-IO>>IDENT-ONS (F)>>IDENT-IO}

Table 4. Constraint tableau: / $\mathrm{Ril}-\int \mathrm{a} \mathrm{Sb} / \rightarrow / \mathrm{Ri} \int \mathrm{Sa} \mathrm{b} /$

\begin{tabular}{|c|c|c|c|c|c|}
\hline /Pil-SaSb/ & $\begin{array}{l}\text { [LAT COR] } \\
\text { SHARE (F) }\end{array}$ & MAX-IO & DEP-IO & IDENT-ONS (F) & IDENT-IO \\
\hline a. PilfaSb & *! & & & & \\
\hline b. Pifacb & & $* !$ & & & \\
\hline c. Pilifạb & & & $*$ & & \\
\hline d. PillaSb & & & & $*$ & * \\
\hline 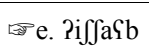 & & & & & * \\
\hline
\end{tabular}

Validating candidate (a) is very hopeless as it breaches the highly ranked constraint [LAT COR] SHARE (F). To escape the adjacency of a lateral and a coronal segment across a morpheme boundary, candidates (b) elides the lateral segment and candidate (c) inserts a vocalic segment to separate the undesired adjacent segments. Neither of them is a good option here as they breach MAX-IO and DEP-IO respectively. Of the remaining two candidates, IDENT-ONS (F) optimizes candidate (e) over (d), by virtue of keeping stem onset features intact.

Another instance where the lateral /// undergoes full assimilation is the dative enclitic $/ 1 /$. The latter undergoes full assimilation when it immediately precedes the alveolar nasal /n/ of the $1^{\text {st }} \mathrm{PL}$ suffix - na. Consider the data in (19).

19)

\begin{tabular}{|c|c|c|}
\hline Input & Output & Gloss \\
\hline 3a:b-ha:-1-na & za:bha:nna & 'he brought it for us' \\
\hline da:rha:-1-na & da:rha:nna & 'he did it for us' \\
\hline ba:?-ha:-1-na & ba:?ha:nna & 'he sold it to us' \\
\hline fra:-1-na & fra:nna & 'he bought for us' \\
\hline
\end{tabular}

Both $/ 1 /$ and $/ \mathrm{n} /$ are [+son] [+cor] and they only differ in the nasal feature in that $/ 1 /$ being [-nas] and $/ \mathrm{n} /$ being [ + nas]. Via assimilation, the nasal feature of $/ \mathrm{n} /$ spreads leftwards to the enclitic $/ 1 /$, yielding the geminate [nn]. To cast this assimilatory process in the light of OT, we may use the same constraint hierarchy established in (18). The reason for using the same constraint hierarchy is that /1/ of both of the definite article /2il/ and the enclitic /1/ fall at a morpheme boundary with the segments they are assimilated to. Table 5 further illustrates how these constraints work to select the optimal candidate from the input /za:bha:-1-na/ 'he brought it for us'.

Table 5. Constraint tableau:/3a:bha:-1-na/ $\rightarrow$ [za:bha:nna]

\begin{tabular}{|c|c|c|c|c|c|}
\hline /3a:bha:-1-na/ & [LAT COR] SHARE (F) & MAX-IO & DEP-IO & IDENT-ONS (F) & IDENT-IO \\
\hline a. za:bha:Ina & $* !$ & & & & \\
\hline b. za:bha:na & & $* !$ & & & \\
\hline c. za:bha:lina & & & $*$ & & $*$ \\
\hline d. za:bha:lla & & & & & $*$ \\
\hline e. za:bha:nna & & & & & $*$ \\
\hline
\end{tabular}

As clearly demonstrated in the table above, candidates (a) and (b) are ruled out as they blatantly violate [LAT COR] SHARE (F) and MAX-IO respectively. Even though, candidate (c) does respect the highly ranked constraints, it is excluded as it violates DEP-IO by inserting a vocalic segment to separate the lateral and the nasal segments. Candidate (d) is ousted from the competition as it violates IDENT-ONS (F), leaving candidate (e) as the only potential winner by means of incurring the least costly violation. 


\section{3. /t/ Assimilation}

Unlike Standard Arabic where the passive voice is indicated by vowel change, the passive voice in DJ is formed by prefixing the morpheme $/ \mathrm{t} / \mathrm{t}$ to the verb stem. This morpheme undergoes total assimilation when prefixed to stems starting with coronal obstruent segments. Yet, assimilation is blocked when $/ \mathrm{t} /$ is prefixed to non-coronal segments or non-obstruents. Consider the data in (20a) and (20b).

20) (a)

\begin{tabular}{|c|c|c|}
\hline Input & Output & Gloss \\
\hline t-sarqit & ssarqit & 'it has been stolen' \\
\hline t-s'akkar & $\mathrm{s}^{\Upsilon} \mathbf{S}^{\Upsilon}$ akkar & 'it has been closed' \\
\hline 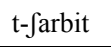 & $\iint a r b i t$ & 'it has been drunk' \\
\hline $\mathrm{t}-\mathrm{t}^{\mathrm{f}}$ algit & $t^{\mathrm{S}} \mathrm{t}^{\mathrm{S}}$ algit & 'she has been divorced' \\
\hline t- $ð^{\text {`arbit }}$ & ðৎðৎarbit & 'she has been beaten' \\
\hline tzawwar & zzawwar & 'it has been counterfeited' \\
\hline
\end{tabular}

(b)

\begin{tabular}{|c|c|c|}
\hline Input & Output & Gloss \\
\hline t-wassxit & twassxit & 'it has been made dirty' \\
\hline t-rafYit & trafYit & 'it has been lifted' \\
\hline t-kitbit & tkitbit & 'it has been written' \\
\hline t-Yarfit & tYarfit & 'she has been known' \\
\hline t-lawnit & tlawnit & 'it has been colored' \\
\hline t-fathit & tfathit & 'it has been opened' \\
\hline t-massit & tmassit & 'it has been touched' \\
\hline
\end{tabular}

It should be still clear from the data above that the prefix / $t$ / is totally homorganic to the following coronal obstruent segments. The data in (20b), however, show that assimilation is blocked when the morpheme $/ t /$ is followed by non-coronal obstruents and sonorant segments. To account for such an assimilatory process within OT, we may refer to a markedness constraint that exerts a high premium on the homogeneity of two adjacent segments. To this end, we again refer to the constraint SHARE (F) and limit the constraint by adapting the left-hand element as the passive voice marker / $t /$ and the right-hand element as the coronal obstruent segments, which can be formulated as in (21).

\section{1) [COR OBS] SHARE (F)}

The passive voice morpheme / $t$ / and the following coronal obstruent segment should share all features when they occur across a morpheme boundary.

This constraint requires the passive voice maker $/ t /$ and the following coronal obstruent to share all features when they occur across a morpheme boundary. Yet, it is in constant conflict with the faithfulness constraint IDENT-IO that requires input and output forms to be identical in feature values. But, as the data in (20a) reveal, [COR OBS] SHARE (F) should outrank IDENT-IO as the former is satisfied at the expense of segmental feature change. Since MAX-IO and DEP-IO dominate IDENT-IO in the dialect grammar, as in (14) and (18), DJ secures [COR OBS] SHARE (F) through assimilation whereby the morpheme / $\mathrm{t} /$ and the following coronal obstruent segments share the same features. Yet, this assimilation can be either regressive or progressive. IDENT-ONS (F), however, cannot determine the assimilation direction this time as both of the morpheme / $t /$ and the following coronal obstruent segment fall in onset position. Since the dialect favors stem faithfulness over affix faithfulness, we are in need for another version of IDENT-IO that strives for keeping stem-onset features intact.

\section{2) IDENT-STEM-ONS (F)}

Every feature of the input stem-onset segment should be kept intact in the output.

\section{3) [COR OBS] SHARE (F) $>>$ MAX-IO $>>$ DEP-IO $>>$ IDENT-STEM-ONS (F) $>>$ IDENT-IO}

The optimization of the output [ssarqit] 'it has been stolen' is elucidated through the interaction of the aforementioned constraints in the following table:

Table 6. Constraint tableau: $/ \mathrm{t}$-sarqit $/ \rightarrow$ [ssarqit $]$

\begin{tabular}{|c|c|c|c|c|c|}
\hline$/$ t-sarqit/ & $\begin{array}{c}\text { [COR OBS] } \\
\text { SHARE (F) }\end{array}$ & MAX-IO & DEP-IO & IDENT-STEM ONS (F) & IDENT-IO \\
\hline a. tsarqit & $* !$ & & & & \\
\hline b. sarqit & & $* !$ & & & $*$ \\
\hline c. tisarqit & & & $*$ & & $*$ \\
\hline d. ttarqit & & & & & $*$ \\
\hline e. ssarqit & & & & & $*$ \\
\hline
\end{tabular}


Candidate (a) is definitely discarded as it breaches [COR OBS] SHARE (F) that is ranked very high. Candidate (b) is also ruled out as it violates MAX-IO. Despite the fact that candidate (c) satisfies the two highly ranked constraints [COR OBS] SHARE (F) and MAX-IO, it is excluded as it contravenes DEP-IO. Candidate (d) is ousted from the competition as it violates IDENT-STEM-ONS (F). Candidate (e), however, bests all its rivals by means of incurring the minimal violation and hence, surfaces as the optimal output. The interacting constraints in the tableau above straightforwardly reveal that DJ opts for changing prefix segment features rather than those of the stem onset which is enforced by [COR OBS] SHARE (F) and IDENT-STEM-ONS.

\subsection{Devoicing Assimilation}

Another instance of regressive assimilation is guttural $^{3}$ devoicing assimilation. In DJ, when the pharyngeal $/ \mathrm{G} /$ is followed by $/ \mathrm{h} /$, the [-voice] feature of $/ \mathrm{h} /$ spreads leftwards to $/ \mathrm{S} /$, yielding $[\hbar \# \# \hbar]$. This can be further illustrated in the data in (24).

24)

\begin{tabular}{|c|c|c|}
\hline Input & Output & Gloss \\
\hline gaS hu:t & gaћ ћu:t & 'all fish' \\
\hline t'las hawwas & t'lah ћawwas & 'he went to look for' \\
\hline rzaৎ ћlu & rzaћ ћlu & 'it becomes sweet' \\
\hline qraS ћli:b & qraћ ћli:b & 'bottles of milk' \\
\hline
\end{tabular}

The voiced pharyngeal / $/$ / gets devoiced when followed by $/ \hbar /$. Both segments share all features except voicing, i.e., both are [pharyngeal] and [+continuant]. By means of regressive devoicing assimilation, the [-voice] feature of the pharyngeal $/ \hbar /$ spreads to the preceding pharyngeal $/ \mathrm{S} /$, yielding [ $\hbar \hbar]$.

DJ also displays another guttural devoicing assimilatory process. When / $/$ / is followed by the pronominal clitics $/ \mathrm{ha} /$ and $/ \mathrm{hum} /$, the [-voice] feature of the $/ \mathrm{h} /$ spreads leftward to $/ \mathcal{S} /$, yielding $[\hbar]$. So, the pharyngeal $/ \mathrm{R} /$ devoices into $/ \hbar /$ and when the latter is followed by $/ \mathrm{h} /$, it triggers place assimilation and results in [ $\hbar$ ] as will be shown in section (3.2). Consider the data in (25).
25)

\begin{tabular}{|c|c|c|}
\hline Input & Output & Gloss \\
\hline ba:?-ha & ba:ћћa & 'he sold it' \\
\hline smi?-ha & smiћћa & 'he listened to it' \\
\hline 3ma?-hum & зmaћћum & 'he gathered them' \\
\hline
\end{tabular}

To capture devoicing assimilation by a constraint, we may formulate a markedenss constraint that requires two contiguous gutturals to be assigned the same token feature of voice. By making recourse to the markedness constraint SHARE (F), we propose the following constraint:

\section{6) GUTTURAL SHARE (voice), hence GUT SHARE (voice)}

Two contiguous guttural sounds should share the same voice feature.

This constraint should be highly ranked in the grammar of DJ as the latter requires two adjacent guttural segments to have the same voicing feature. To abide by this constraint, DJ opts for segmental feature change. Yet, this feature change can either target the coda of the first word and hence, we end up with [gaћ\#\#列] or the onset of the second word,

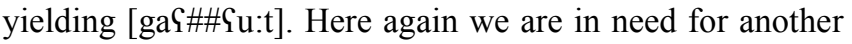
constraint that chooses only one optimized form and decides on the direction of assimilation either regressive or progressive. To optimize [gah\#\#hu:t] over [gaß\#\#ৎu:t], we may refer to the faithfulness constraint IDENT-ONS (F) as the dialect prefers to keep onset features intact as much as possible. With these constraints at play, the following dominance hierarchy is borne out:

\section{7) GUT SHARE \\ (voice) $>>$ MAX-IO $>>$ DEP-IO $>>$ IDENT-ONS (F) $>>$ IDENT-IO}

Table 7 examines the efficiency of such a constraint hierarchy in optimizing the desired output from/ga? hu:t/ 'all fish'

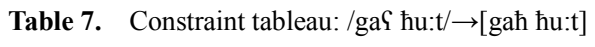

\begin{tabular}{|c|c|c|c|c|c|}
\hline $\begin{array}{c}\text { /gaS } \\
\text { hu:t/ }\end{array}$ & $\begin{array}{c}\text { GUT } \\
\text { SHARE } \\
\text { (voice) }\end{array}$ & MAX-IO & DEP-IO & $\begin{array}{c}\text { IDENT- } \\
\text { ONS } \\
\text { (F) }\end{array}$ & IDENT-IO \\
\hline $\begin{array}{c}\text { a. ga؟ } \\
\text { hu:t }\end{array}$ & $* !$ & $* !$ & $*$ & & \\
\hline $\begin{array}{c}\text { b. ga } \\
\text { hu:t }\end{array}$ & & & $*$ & $*$ \\
\hline $\begin{array}{c}\text { c. gaYi } \\
\text { hu:t }\end{array}$ & & & & & $*$ \\
\hline $\begin{array}{c}\text { d. ga؟ } \\
\text { Gu:t } \\
\text { e. gah } \\
\text { hu:t }\end{array}$ & & & & & \\
\hline
\end{tabular}


Candidate (a) and (b) are radically excluded as they fatally breach GUT SHARE (voice) and MAX-IO that are ranked higher in the dialect grammar. Candidate (c) is discarded by incurring a violation of DEP-IO. IDENT-ONS (F) breaks the tie between the candidates (d) and (e) by excluding candidate (d) from the competition, leaving candidate (e) as the only potential winner.

As demonstrated in this section, regressive assimilation is very pervasive in DJ and this is mainly owing to IDENT-ONS (F) that endeavors to keep onset segment features intact.

\section{Progressive Assimilation in DJ}

\subsection{Emphasis Assimilation}

Progressive assimilation is less common in DJ. One of the most attested instantiations of progressive assimilation is emphasis spread (ES). Throughout the literature, emphasis harmony took different labels, viz., pharyngealization [7], [8], [9] and [10] and uvularization [11]. Despite the fact that emphatic segments are articulated with some constriction in the pharynx, we believe that referring to ES in terms of the feature [Pharyngeal] is very vague. Thus, following [10], we approach this emphasis assimilatory process in terms of the spread of the [RTR] feature of the underlying emphatic segment to color the neighboring segments. In the current paper, however, we will restrict the discussion of emphasis harmony to $\mathrm{CV}$ domain ${ }^{4}$ by showing how the plain vowel /a/ gets emphaticized when it crops up in the vicinity of emphatic consonants. In this vein, when the plain vowel /a/ is adjacent to an underlying emphatic consonant, the [RTR] feature of the emphatic consonant spreads rightwards to $/ \mathrm{a} /$, yielding $[a]$. Consider the data in (28).

28)

\begin{tabular}{|c|c|c|}
\hline Input & Output & Gloss \\
\hline t $^{\text {} a}$ a:bis & $t^{\varsigma} a: b i \varsigma$ & 'stamp' \\
\hline$t^{\text {`ajjab }}$ & $t^{\uparrow} a j j a b$ & 'he cooked' \\
\hline$s^{\Upsilon} a: m$ & $s^{\varsigma} a: m$ & 'he fasted' \\
\hline $\mathrm{s}^{\text {`a:hib }}$ & $s^{\varsigma} a: \hbar i b$ & 'friend' \\
\hline ð`ajja؟ & $\partial^{\varsigma}$ ajjaৎ & 'he lost sth' \\
\hline$\partial \partial_{\text {alma }}$ & dৎalma & 'darkness' \\
\hline
\end{tabular}

To account for this progressive assimilation in the light of OT, we may again refer to the markedness constraint SHARE (F) and propose the following constraint:

\section{9) SHARE (RTR)}

Assign a violation to any $\mathrm{CV}$ sequence that is not linked to the same token RTR/ATR feature.

This constraint requires two adjacent segments (a consonant and a vowel) to share the same feature of [RTR]. But this constraint runs against IDENT-IO that necessitates

4 For the purpose of this paper, we restrict the domain of emphasis spread to $\mathrm{CV}$ domain, leaving long-distance emphasis harmony for further research. the congruency between input and output. Yet, SHARE (RTR) can be either satisfied by de-emphaticizing the underlying emphatic consonant or emphaticizing the plain vowel. Consequently, two versions of IDENT-IO should come to play.

\section{0) IDENT(+RTR)}

$[+\mathrm{RTR}]$ segments in the input must remain $[+\mathrm{RTR}]$ in the output.

\section{1) IDENT(-RTR)}

[-RTR] segments in the input must remain [-RTR] in the output.

In terms of constraint ranking, IDENT (+RTR) should be undominated in the dialect as the latter strives for keeping the [+RTR] feature of the underlying emphatic segments intact. Since SHARE (RTR) is satisfied by spreading the [+RTR] specification to the adjacent plain segment, IDENT (-RTR) should be demoted in the dialect.

The ranking permutation of the constraints governing such an assimilatory process is established in (32).

\section{2) IDENT(+RTR)>>SHARE(RTR)>>IDENT(-RTR)}

Table 8. Constraint tableau: $/ \mathrm{t}^{\mathrm{f}} \mathrm{a} / \rightarrow\left[\mathrm{t}^{\mathrm{c}} \mathrm{a}\right]$

\begin{tabular}{|c|c|c|c|}
\hline$/ \mathrm{t}^{\mathrm{a}} \mathrm{a}$ & $\begin{array}{c}\text { IDENT } \\
(+\mathrm{RTR})\end{array}$ & $\begin{array}{c}\text { SHARE } \\
(\mathrm{RTR})\end{array}$ & $\begin{array}{c}\text { IDENT } \\
(-\mathrm{RTR})\end{array}$ \\
\hline a. $\mathrm{ta}$ & $* !$ & & \\
\hline b. $\mathrm{t}^{\mathrm{a}} \mathrm{a}$ & & $* !$ & \\
\hline c. $\mathrm{t}^{\mathrm{f}} \mathrm{a}$ & & & $*$ \\
\hline
\end{tabular}

Candidate (a) is ruled out as it fatally violates the highly ranked constraint IDENT (+RTR). Although being faithful to the input, candidate (b) is ousted from the competition as the $\mathrm{CV}$ sequence in the output $\left[\mathrm{t}^{\mathrm{f}} \mathrm{a}\right]$ is not specified for the same token of the feature [RTR]. Candidate (c), however, surfaces as the optimal output as it incurs the least violation.

\subsection{Guttural Place Assimilation}

In $\mathrm{DJ}$, the laryngeal sound $/ \mathrm{h} /$ of the pronominal clitic [-hum-] [-ha-] also undergoes place assimilation when preceded by $/ \hbar /$ and $/ \mathrm{x} /$, yielding [ $\hbar \hbar]$ and $[\mathrm{xx}]$ respectively. Consider the data in (33).

33)

\begin{tabular}{|c|c|c|}
\hline Input & Output & Gloss \\
\hline la:h-hum & la:hћum & 'he threw them' \\
\hline st ${ }^{\mathrm{f}} \mathrm{ah}-\mathrm{hum}$ & $s t^{\uparrow} a \hbar \hbar u m$ & 'their ceiling' \\
\hline wassax-ha & wassaxxa & 'he made it dirty' \\
\hline
\end{tabular}

As revealed in the data above, the voiceless laryngeal $/ \mathrm{h} /$ undergoes place assimilation when preceded by the voiceless gutturals $/ \mathrm{x} /$ and $/ \mathrm{h} /$. All these three gutturals share the same voicing feature [-voice], in addition to the feature [+cont], they only differ in the place of articulation; $/ \mathrm{h} /$ being 
laryngeal, $/ \mathrm{x} /$ being uvular and $/ \mathrm{h} /$ being pharyngeal. To account for this place assimilatory process, we may propose the constraint CONTINUANT GUTTURAL SHARE (place) that requires two adjacent continuant gutturals to share the same place feature. This constraint is formulated in (34).

\section{4) CONTINUANT GUTTURAL SHARE (place) (CONT-GUT SHARE (place))}

Across a morpheme boundary, two adjacent continuant gutturals should share the same place of articulation.

This constraint militates against IDENT-IO which is ranked very low in the hierarchy. Another way to avoid the banned adjacency of these segments is either by epenthesizing a vocalic segment between them or by deleting one of the contiguous gutturals, but such an insertion or deletion yields ungrammatical outputs such as *[la:hiha] and *[la:ha] and militates against DEP-IO and MAX-IO respectively. In order to avoid the banned adjacency of two continuant gutturals involving different places of articulation, DJ rather resorts to progressive place assimilation whereby the place features of $/ \mathrm{x} /$ and $/ \mathrm{h} /$ spreads rightwards to $/ \mathrm{h} /$, yielding $[\mathrm{xx}]$ and $[\hbar \hbar]$ respectively. After figuring out the relevant constraints, the following constraint hierarchy is adduced.

\section{5) CONT-GUT SHARE}

(place) $>>$ MAX-IO $>>$ DEP-IO $>>$ IDENT-ONS (F) $>>$ IDENT-IO

Table 9 further illustrates how these faithfulness and markedness constraints interact to optimize the desired output from the input /la:h-ha/ 'he threw it'.

Unexpectedly, the constraint interaction in the hierarchy established in (35) fails to produce the desired output [la:tћa].

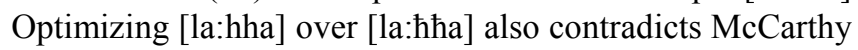
and Prince's (1995) claim that root faithfulness should outrank affix faithfulness. To get the desired output optimized, we are in need for a constraint that strives for keeping stem segment features intact; namely, IDENT-STEM (F). This version of IDENT-IO should be ranked higher than IDENT-ONS (F) otherwise, [la:hha] will be optimized over [la:ћћa].

\section{6) IDENT-STEM (F)}

Every segment of the input stem should be kept intact in the output.

\section{7) CONT-GUT SHARE (place) $>>$ MAX-IO $>>$ DEP-IO $>>$ IDENT-STEM (F) $>>$ IDENT-ONS (F) $>>$ IDENT-IO}

The constraints interaction in table 10 further elucidates the optimization of [la: $\hbar \hbar a]$ over [la:hha].

The ranking IDENT-STEM (F)>>IDENT-ONS (F) optimizes candidate (e) over candidate (d). The fact that CONT-GUT SHARE (place) is satisfied at the cost of IDENT-ONS (F) indicates that the dialect strives for keeping onset features intact unless a higher ranked constraint is endangered.

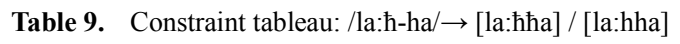

\begin{tabular}{|c|c|c|c|c|c|}
\hline /la:h-ha/ & $\begin{array}{l}\text { CONT-GUT SHARE } \\
\text { (place) }\end{array}$ & MAX-IO & DEP-IO & IDENT-ONS (F) & IDENT-IO \\
\hline a.la:ћha & $* !$ & & & & \\
\hline b.la:ћa & & $* !$ & & & \\
\hline c.la:hiha & & & $*$ & & \\
\hline (i) d. la:ћћa & & & & $*$ & $*$ \\
\hline e.la:hha & & & & & $*$ \\
\hline
\end{tabular}

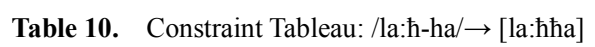

\begin{tabular}{|c|c|c|c|c|c|c|}
\hline $\begin{array}{c}\text { Input } \\
\text { /la:h-ha/ }\end{array}$ & $\begin{array}{l}\text { CONT-GUT SHARE } \\
\text { (place) }\end{array}$ & MAX-IO & DEP-IO & IDENT-STEM (F) & $\begin{array}{l}\text { IDENT- } \\
\text { ONS (F) }\end{array}$ & IDENT-IO \\
\hline a. la:‡ha & $* !$ & & & & & \\
\hline b. la:ћa & & $* !$ & & & & \\
\hline c. la:hiћa & & & $*$ & & & \\
\hline d. la:hha & & & & $*$ & & $*$ \\
\hline e. la:ћћa & & & & & * & * \\
\hline
\end{tabular}




\section{Conclusions}

In the foregoing discussion, we have addressed some regressive and progressive assimilation in DJ. Couched within the OT framework, the analysis showed how the markedness and the faithfulness constraints are conflicting to yield the optimal outputs attested in the dialect. So far, we have accounted for the trigger that motivates such assimilatory processes and we showed that regressive assimilation is very pervasive in the dialect as the latter endeavors to abide by IDENT-STEM-ONS (F) and IDENT-ONS (F) as much as possible. Moreover, the paper lends support to McCarthy and Prince's (1995) claim that root faithfulness outranks affix faithfulness as DJ prefers to keep stem segment features intact at the expense of affixes feature change.

Nasal assimilation, lateral assimilation, / $t /$ assimilation, devoicing assimilation and guttural place assimilation discussed in this paper are accounted for by the following constraint hierarchy:

\section{8) N-O SHARE (place), *N+SC, [LAT COR] SHARE (F), [COR OB] SHARE (F), GUT SHARE (voice), CONT-GUT SHARE \\ (place) $>>$ MAX-IO $>>$ DEP-IO $>>$ IDENT-STEM-ON S (F) $>>$ IDENT-STEM (F) $>>$ IDENT-ONS (F) $>>$ IDENT-IO.}

Table 11 further recapitulates the interaction of these constraints.

Table 11. Tableau constraint

\begin{tabular}{|c|c|c|c|c|c|c|c|c|}
\hline & Input & $\begin{array}{c}\text { N-O SHARE (place), *N+SC, [LAT COR] SHARE (F), } \\
\text { [COR OB] SHARE (F), } \\
\text { GUT SHARE (voice), } \\
\text { CONT-GUT SHARE (place) }\end{array}$ & $\begin{array}{l}\text { MAX- } \\
\text { IO }\end{array}$ & $\begin{array}{l}\text { DEP } \\
\text { - IO }\end{array}$ & $\begin{array}{l}\text { IDENT- } \\
\text { STEM- } \\
\text { ONS(F) }\end{array}$ & $\begin{array}{l}\text { IDENT } \\
\text {-STEM } \\
\text { (F) }\end{array}$ & $\begin{array}{l}\text { IDENT } \\
\text {-ONS } \\
\text { (F) }\end{array}$ & $\begin{array}{l}\text { IDENT } \\
- \text { IO }\end{array}$ \\
\hline \multirow{6}{*}{1} & /qanbu:la/ & & & & & & & \\
\hline & a. qanbu:la & N-O SHARE (place)! & & & & & & \\
\hline & b. qabu:la & & $* !$ & & & & & \\
\hline & c. qanibu:la & & & * & & & & \\
\hline & d. qandu:la & & & & * & $*$ & * & * \\
\hline & e. qambu:la & & & & & $*$ & & * \\
\hline \multirow{6}{*}{2} & /min ra:h/ & & & & & & & \\
\hline & a. $\min$ ra:h & *N+SC! & & & & & & \\
\hline & b. mi ra:h & & $* !$ & & & & & \\
\hline & c. mini ra:h & & & * & & & & \\
\hline & d. min na:h & & & & * & * & * & * \\
\hline & e. mir ra:h & & & & & & & $*$ \\
\hline \multirow[t]{6}{*}{3} & /Ril-faGb/ & & & & & & & \\
\hline & a. PilfaSb & [LAT COR] SHARE (F)! & & & & & & \\
\hline & b. ?ijąb & & $* !$ & & & & & \\
\hline & c. PilifaYb & & & * & & & & \\
\hline & d. PillaYb & & & & * & * & * & * \\
\hline & 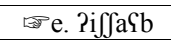 & & & & & & & $*$ \\
\hline \multirow{6}{*}{4} & /za:bha:-1-na/ & & & & & & & \\
\hline & a. za:bha:Ina & [LAT COR] SHARE (F)! & & & & & & \\
\hline & b. za:bha:na & & $* !$ & & & & & \\
\hline & c. za:bha:lina & & & $*$ & & & & \\
\hline & d. za:bha:lla & & & & & & $*$ & $*$ \\
\hline & $\begin{array}{c}\text { e. } \\
\text { za:bha:nna }\end{array}$ & & & & & & & * \\
\hline \multirow{6}{*}{5} & /t-sarqit/ & & & & & & & \\
\hline & a. tsarqit & [COR OB] SHARE (F)! & & & & & & \\
\hline & b. sarqit & & $* !$ & & & & & \\
\hline & c. tisarqit & & & * & & & & \\
\hline & d. ttarqit & & & & * & $*$ & * & * \\
\hline & e. ssarqit & & & & & & * & $*$ \\
\hline \multirow{6}{*}{6} & /gaS\#\# ћu:t/ & & & & & & & \\
\hline & a. gaY hu:t & GUT SHARE (voice)! & & & & & & \\
\hline & b. ga ћu:t & & $* !$ & & & & & \\
\hline & c. gaYi hu:t & & & $*$ & & & & \\
\hline & d. ga؟ Gu:t & & & & * & * & * & * \\
\hline & e. gaћ ћu:t & & & & & & & $*$ \\
\hline \multirow{6}{*}{7} & /la:h-ha/ & & & & & & & \\
\hline & a. la:ћha & CONT-GUT SHARE (place)! & & & & & & \\
\hline & b. la:ha & & $* !$ & & & & & \\
\hline & c. la:hiha & & & $*$ & & & & \\
\hline & d. la:hha & & & & & $*$ & & $*$ \\
\hline & e. la:tha & & & & & & * & * \\
\hline
\end{tabular}


So far, as it turns out from table 11, DJ prefers stem-faithfulness over affix faithfulness. Moreover, DJ strives for keeping onset features intact and this is mainly elucidated through the evaluator's (Eva) endeavor to rule out candidates breaching IDENT-STEM-ONS (F) and IDENT-ONS (F) as much as possible, unless a higher ranked constraint compels such a violation.

\section{REFERENCES}

[1] Prince, Alan, and Paul Smolensky. 1993. Optimality Theory: Constraint Interaction in Generative Grammar. Ms., Rutgers University, New Brunswick, N.J. and University of Colorado, Boulder. MIT Press.

[2] McCarthy, J.J. and Prince, A.1993a. Generalized alignment. In Yearbook of morphology 1993, ed. Geert Booij and Jaap van Marle, 79-153. Dordrecht: Kluwer.

[3] McCarthy, J.J. and Prince, A.1993b. Prosodic morphology I: Constraint interaction and satisfaction. Ms., University of Massachusetts, Amherst, and Rutgers University, New Brunswick, N.J.
[4] McCarthy, J.J. and Prince, A. 1995. Faithfulness and Reduplicative Identity. MS. University of Massachusetts, Amherst, and Rutgers University.

[5] McCarthy, John J.2011. Autosegmental spreading in Optimality Theory. Availale at:

https://works.bepress.com/john_j_mccarthy/100/.

[6] Kenstowicz, M. 1994. Phonology in Generative Grammar (Cambridge, Mass., Oxford: Blackwell.

[7] Ali, Latif and Daniloff, R. G. 1972. A contrastive cinefluorographic investigation of the articulation of emphatic-non emphatic cognate consonants. Studia Linguistica 26:81-105.

[8] Giannini, A., Pettorino, M. 1982. The emphatic consonants in Arabic. Speech Laboratory Report IV, Istituto Universitario Orientale di Napoli.

[9] Al-Ani, S. 1970. Arabic phonology. The Hague: Mouton

[10] Davis, Stuart. 1995. Emphasis Spread in Arabic and Grounded Phonology. Linguistic Inquiry 26:3(465-498).

[11] Zawaydeh, Bushra. 1998. Gradient Uvularization Spread in Amm

[12] Ani Jordanian Arabic. Perspectives on Arabic linguistics XI, ed. Elabbas Benmamoun, Mushira Eid, and Niloofar Haeri. Amsterdam: John Benjamins: 117-141 